\title{
Assessing the knowledge, perceptions and practices in advance care planning: a comparison between American and Japanese physicians
}

\begin{abstract}
The global trend of a rapidly aging population in developed countries has resulted in an unmet need for healthcare professionals trained in advance care planning (ACP). To reveal driving and restraining forces of ACP physician to patient communication and ascertain training receptivity, this study explored the differences in the approaches and perceptions of ACP between physicians in a Japanese Medical Center, Japan $(n=71)$, and a United States Medical Center, US ( $n=83)$. Data was collected using an online survey administered in 2015 which included both qualitative and quantitative questions. Thematic coding techniques were employed to analyze the qualitative responses and independent samples t-tests and chi-squared tests were applied for quantitative analysis. Findings revealed that American physicians were significantly more likely than Japanese physicians to be satisfied with their understanding of their patient population's cultural perspectives of ACP $(p<.001)$. While no significant association $(p=.242)$ could be ascertained on their perceived value for additional training on ACP, the average response indicated they thought that such training would at least be moderately helpful. American physicians were also significantly more likely to have advance directives than their Japanese counterparts $(p<.001)$. The results highlighted the continued ambivalent nature of discussions on death and dying, underscoring the need to improve physicians' preparedness for ACP in both Japan and the United States of America (USA). Future studies should investigate the efficacy of measures used for such additional training.
\end{abstract}

Keywords: Japan, united states, advance care planning, training, physicians, perceptions, knowledge, receptivity, end of life care
Volume I Issue 2 - 2017

\author{
Brenda Freshman, Author Yao \\ Department of Health Care Administration, California State \\ University, USA
}

\begin{abstract}
Correspondence: Brenda Freshman,Associate Professor, Department of Health Care Administration, Research Director, Ukleja Center for Ethical Leadership, California State University, Long Beach, 1250 Bellflower Boulevard, Mailstop 4904, CA 90840-000I, USA, Tel 310-498-3829, Email Brenda.Freshman@csulb.edu
\end{abstract}

Received: June 16,2017 | Published: July 06, 2017
Abbreviations: ACP, advance care planning; CMO, chief medical officer; ICU, intensive care unit

\section{Introduction}

Advance care planning (ACP) has been described as a social process whereby patients prepare for incapacity or death to ease the burden placed on their loved ones, which is typically but not exclusively performed by completing advance directives. ${ }^{1}$ The global trend of a rapidly aging population has introduced an unmet need for healthcare professionals trained in advance care planning. Perhaps no country better reflects this dilemma than Japan, where the population currently faces one of the highest proportion of aging citizens, with more than one-in-five (23\%) people being at least 65 or older. ${ }^{2}$ Although the United States has a comparatively smaller proportion of elderly citizens (13\%), projections reveal that the proportion will continue to increase in the coming years. ${ }^{2,3}$ Both Japan and the United States were therefore selected for further analysis to assess the differences in the levels of preparedness among physicians for advance care planning.

Previous studies have cited insufficient training, ${ }^{4}$ incomplete documentation, ${ }^{5}$ lack of knowledge of patient preference, ${ }^{6}$ deficiency of discussion, ${ }^{7}$ and influence of religious affiliations ${ }^{8}$ as examples among several of the challenges indicated. For example, in one study, it was found that physicians had no knowledge of their patients' preferences; there were no effective communications between physicians and their patients concerning terminal care. ${ }^{9}$
On the other hand, another study discovered severe deficiencies in communication between clinicians and their patients, where every topic pertaining to end-of-life care was found to be under addressed, despite having received training on the matter. ${ }^{7}$ A concerning incongruity was also noted between physicians' religiosity and patients' end-of-life care preferences, such that physicians' religiosity had the potential of influencing their end-of-life care in a manner that was inconsistent with what patients preferred. ${ }^{8}$ Along these lines another study reported strong recommendations to engage in a shared approach to end-of-life care and decision-making, where patient autonomy should be stressed to the family. ${ }^{6}$

Additional findings have indicated that giving physicians systematic support for appropriate decision-making on end-of-life care would be greatly beneficial. ${ }^{10}$ Although most Japanese palliative care physicians recognized the importance of ACP, many failed to implement the very aspects of ACP that they recognized as important. ${ }^{11}$ This study therefore investigated how physicians would feel about additional training in ACP, as well as their specific topics of interest.

\section{Methods}

\section{Participants}

Participants included 71 multispecialty physicians recruited from a 965-bed medical center in the Chiba Prefecture, Japan and 123 multispecialty physicians recruited from a 458-bed urban medical center in Southern California, USA. 


\section{Design}

The study employed a cross-sectional survey that was administered online using Qualtrics Survey Software in 2015. To recruit participants, an email invitation was dispatched three times over a sixweek period from the medical staff office of each respective medical center. A total of 400 Japanese physicians and 1,164 US physicians were invited. Of that amount, 71(17.75\%) Japanese physicians and $123(11.2 \%)$ US physicians responded. The survey protocol was reviewed and approved by the institutional review board of California State University, Long Beach, US. Institutional review and approval was also granted from the two medical centers.

\section{Survey instrument}

The survey instrument assessed the state of advance care planning in each facility, including questions on physician engagement and training receptivity. General demographics of the respondents were also collected. The survey was comprised of a combination of 31 quantitative and qualitative questions, including Likert scale, checkbox, and open-ended text items (Appendix A for survey items).

\section{Instrument overview}

The survey asked questions regarding the current practices of physicians when it came to their discussions with their patients on ACP and advance directives. For example, questions such as, "How routinely do you discuss advance care planning issues with patients?" "How do you most commonly access a patient's advance directive?" and "If there is not an advance directive on file for a patient, what do you do?" were included. To better apprehend the extent of the physicians' understanding and participation in these topics, questions such as, "Have you had any education/training in palliative care?" and "What conditions would need to exist for you to contact the Palliative Care Team?" were asked. Other questions about the awareness and practices of physicians included the extent of their ACP training, whether they ever contacted the Palliative Care Team in their medical center, and the barriers to doing so. Furthermore, physicians were queried whether they themselves had an $\mathrm{AD}$ on file and where it was located.

The survey also included questions that probed into what physicians viewed as their greatest challenge with respect to ACP communication. These questions ranged from a direct question on "What is your biggest challenge when discussing advance care planning with patients and families?" to other specific issues, such as what physicians perceived as opportunities for improvement, how they believed their personal philosophy could impact ACP conversations and management, and the extent of awareness for various types of ACP resources for patients, their families, and the physicians themselves.

To ensure that findings would be actionable, additional probing questions to gauge the physicians' receptivity to ACP communication training, as well as their preferences for the type of intervention, were also asked. These questions included how helpful the physicians felt additional ACP education would be for them, the specific types of topics they would like to learn more about, and their delivery format of preference.

Finally, general demographics were collected through questions about the physicians' practice group, age range, ethnicity, spiritual and religious affiliations, native country, and gender. To develop the survey instrument, the chief medical officer (CMO) of the Southern California Medical Center was consulted for an initial draft of the survey. After which the survey was pilot tested with four focus groups comprised of multispecialty physicians invited by the CMO. These focus groups encompassed the top four specialties that consistently participated in the ACP process at the US facility: intensive care unit (ICU), hospitalists, primary care, and oncology. An average of 5 physicians in each focus group provided recommendations on the assessment which was then revised based on their feedback and further consultation with the CMO.

An executive team including the Executive Vice President of the Japanese Medical Center also conducted a review of the instrument. To accommodate Japanese physicians, the survey was translated by an independent consultant into the Japanese language. Following the translation, the executive team reviewed the survey once more to ensure cohesiveness.

\section{Analysis}

All quantitative analyses were performed in SPSS 22.0 software. Descriptive statistics were conducted to examine the responses and demographics of the physician participants, specifically for race, age, sex, religion, and the frequencies for questions such as the perceived top 5 most valuable topics on which to receiving training. Chisquared tests were employed to determine significant associations in categorical items such as a physicians' likelihood of having an $\mathrm{AD}$ on file for themselves based on their country of residence and age. Independent samples t-tests were used to determine any significant differences in quantitative scale items. For example a t-test was conducted on the global score composite of items regarding the overall level of satisfaction of respondents' understanding of their patient population's cultural perspectives regarding ACP and their perceived value of additional training.

Open-ended text items were qualitatively analyzed through thematic coding and analysis, using an Excel-based algorithm that calculated the frequencies of themes after the responses were manually coded. The thematic analysis was conducted primarily to supplement understanding on current practices, perceived barriers, and to clarify future training topics that physicians believed would be most helpful to facilitate their communication with patients.

\section{Results}

The completion rate of the survey was $66.2 \%(n=47)$ for Japanese physicians and $67.5 \%(n=83)$ for US physicians.

\section{Demographic data}

An overview of the demographics data can be found in Table 1. The surveyed physicians in the US were mostly White, male, Christian, and fell in the age range 51-65. Japanese physicians were more homogeneous, with virtually all respondents being Asian, mostly male, non-religious, and younger than the US physicians with an age range of 20-35 years old.

\section{Quantitative results}

Physicians' educational and training experience with ACP: Nearly half of Japanese physicians $(49 \%, n=71)$ and many American physicians $(31 \%, n=48)$ reported that they never had any training for palliative care/ACP in the past. 
Table I Description of Japanese and American physicians' characteristics

\begin{tabular}{lll}
\hline Variable & Japan & US \\
\cline { 2 - 3 } Gender & $\mathbf{n}(\%)$ & $\mathbf{n}(\%)$ \\
Female & $\mathrm{I} 8(27.7)$ & $\mathbf{N}=\mathbf{2 7}(35.5)$ \\
Male & $47(72.3)$ & $49(64.5)$ \\
Age,Years & $\mathbf{N}=70$ & $\mathbf{N}=79$ \\
20-35 & $4 \mathrm{I}(58.6)$ & $\mathrm{II}(\mathrm{I} 3.9)$ \\
36-50 & $26(37 . \mathrm{I})$ & $25(3 \mathrm{I} .6)$ \\
$5 \mathrm{I}-65$ & $2(2.9)$ & $33(4 \mathrm{I} .8)$ \\
66-80 & $\mathrm{I}(\mathrm{I} .4)$ & $\mathrm{I} 0(\mathrm{I} 2.7)$ \\
Race & $\mathbf{N}=68$ & $\mathbf{N}=75$ \\
Asian & $68(\mathrm{I} 00)$ & $\mathrm{II}(\mathrm{I} 4.7)$ \\
White & $0(0)$ & $52(69.3)$ \\
Latino & $0(0)$ & $8(\mathrm{I} 0.7)$ \\
Other & $0(0)$ & $4(5.3)$ \\
Religion & $\mathbf{N}=32$ & $\mathbf{N}=73$ \\
Buddhism & $9(28 . \mathrm{I})$ & $0(0)$ \\
Catholic & $\mathrm{I}(3 . \mathrm{I})$ & $\mathrm{II}(\mathrm{I})$ \\
Christian & $0(0)$ & $30(4 \mathrm{I} . \mathrm{I})$ \\
Jewish & $0(0)$ & $\mathrm{I} 0(\mathrm{I} 3.7)$ \\
None/NA & $22(68.8)$ & $20(27.4)$ \\
Other & $0(0)$ & $2(2.7)$ \\
\hline
\end{tabular}

Association with physicians' country, age and having an AD: The chi-squared tests revealed that there was a significant association between having an advance directive on file and the country of the physician, where Japanese physicians were significantly less likely than American physicians to have an advance directive on file for themselves $(p<.001, N=143)$. There were, however, no significant associations between having an advance directive on file and the age of the physician $(p=.870, N=74)$.

Physicians' understanding of cultural perspectives on ACP: The independent samples t-tests showed a significant difference in satisfaction on the level of understanding of the patient population's cultural perspectives regarding ACP for Japanese physicians $(M=2.08$, $\mathrm{SD}=.816, n=59)$ and American physicians $(M=2.77, S D=.831, n=44)$; $\mathrm{t}(101)=-4.20, p<.001$, where Japanese physicians were less satisfied with their understanding than American physicians.

Physicians' perceived value of additional ACP training: There was no significant difference in perceived value of more training for Japanese physicians $(M=2.67, \mathrm{SD}=.771, n=55)$ and American physicians $(M=2.87, \mathrm{SD}=.909, n=46) ; \mathrm{t}(99)=-1.18, p=.242$, however, physicians from both countries reported that such training would contribute to enhance their understanding of advance care planning.

Physicians' self-reported 5 most valuable topics for additional training: Japanese physicians felt the top 5 most valuable topics, in order, were: 1) Interpersonal communication skills; 2) How to have difficult conversations; 3) Breaking the "bad" news"; 4) Managing patient/family expectations; and 5) Cultural perspectives on death \& dying. American physicians felt the top 5 were: 1) Cultural perspectives on death \& dying; 2) Spiritual/religious perspectives on death \& dying; 3) Managing patient and family expectations; 4) Optimizing patient visits for crucial conversations; and 5) How to have difficult conversations (Figure 1).

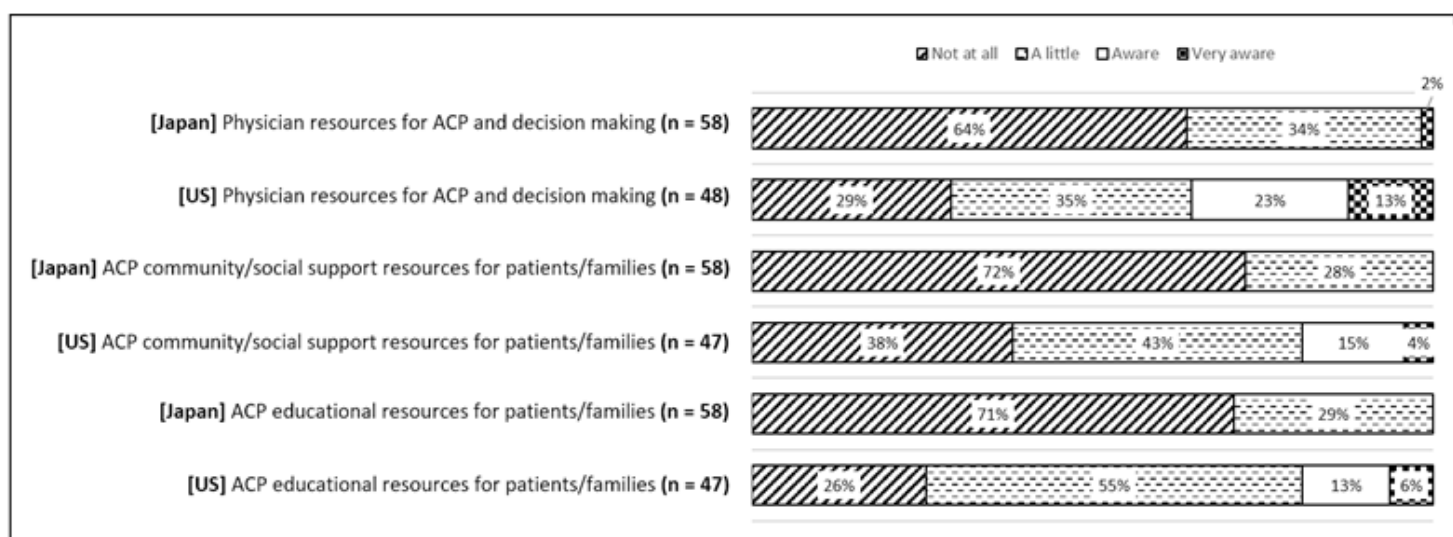

Figure I Physicians' extent of awareness of select resources on advance care planning.

\section{Qualitative results}

\section{Biggest challenge to ACP discussions}

The top two recurring themes among Japanese physicians in response to their biggest challenge when discussing advance care planning with patients and their families were 1) inadequate time $(20 \%)$ and 2) upsetting the patient (18\%). Among the American physicians, the top challenges were 1) inadequate time (27\%) and 2) patient/family unwillingness due to stress (25\%). Following below are example quotes from physician responses corresponding to these themes; see Table 2 for an overview of thematic comparisons for select queries.

1) Inadequate time to discuss ACP (Japanese physicians)

i. "Opportunity to bring up the conversation."

ii. "Time of conversation when patients are visiting as outpatient."

iii. "Creating a calm environment to speak; the timing."

iv. "It is hard to know the best way to discuss and the timing." 
v. "Timing/cannot take care of outpatient/or has no family in attendance."

2) Upsetting the patient (Japanese physicians)

i. "Bringing up the topic could make the patient feel worse."

ii. "If talk to the acute patients the wrong way they may become depressed or angry."

iii. "They cannot accept that medicine has limitations."

1) Inadequate time to discuss ACP (American physicians)

i. "Finding time to approach the subject during a regular clinic visit."

ii. "The time it takes to go through it all. Limited time for this in a patient visit." iii. "Finding appropriate time to have discussion."

2) Patient/family unwillingness due to stress (American physicians)

i. "They don't want to talk about it or state not now."

ii. "Difficulty in the emergency department. Often patient and family are in a stressful situation and bringing up advance care setting can be difficult."

iii. "Understanding of families as this is a difficult topic for parents to accept when dealing with a critically ill newborn, or one with an illness that is felt to be terminal."

iv. "Patient/family's reluctance to address this issue when presented in the context of future possible negative patient outcomes..."

Table 2 Thematic comparison of Top 3 themes from physicians' responses

\begin{tabular}{|c|c|c|c|c|}
\hline & Japan & $n(\%)$ & US & $n(\%)$ \\
\hline \multirow{3}{*}{$\begin{array}{l}\text { What is your biggest challenge when } \\
\text { discussing ACP with patients and } \\
\text { families? }\end{array}$} & Not enough time & $9(20)$ & Not enough time & $21(28)$ \\
\hline & Upsetting patient & $8(18)$ & Patient unwilling/too stressed & $19(25)$ \\
\hline & Upsetting self & $7(16)$ & Not appropriate for specialty & $9(12)$ \\
\hline \multirow{3}{*}{$\begin{array}{l}\text { At what point in the care of your patient } \\
\text { do you initiate a conversation about } \\
\text { palliative care? }\end{array}$} & Patient is hospitalized & $15(36)$ & Multiple chronic conditions & $12(27)$ \\
\hline & Patient is terminal & $9(2 I)$ & Near death/terminal & $9(20)$ \\
\hline & At any possible time & $6(14)$ & When palliative care is needed & $6(13)$ \\
\hline \multirow{3}{*}{$\begin{array}{l}\text { Please describe any barriers to using } \\
\text { [Palliative Care Team] services. }\end{array}$} & Benefits are unknown & $4(22)$ & No barriers & $7(16)$ \\
\hline & Patient reluctance & $4(22)$ & Other physician resistance & $3(7)$ \\
\hline & Contact is difficult & $3(17)$ & $\begin{array}{l}\text { Positive experience with team } \\
\text { (not a barrier) }\end{array}$ & $3(7)$ \\
\hline
\end{tabular}

\section{Point in time when palliative care conversation is initiated}

The top two recurring themes among Japanese physicians describing the point in care when they initiate conversation about palliative care were 1) when patient is hospitalized (36\%) and 2) when patient is terminal (21\%). In comparison, among American physicians reported 1) when patient has multiple chronic conditions (27\%) and 2 ) when patient is near death or terminal $(20 \%)$. Below are select quotes from respondents corresponding to each of the aforementioned themes.

1) When patient is hospitalized (Japanese physicians)

i. "Early when the patient is hospitalized and depending on the situation."

ii. "On hospitalization."

iii. "The time when patient is hospitalized."

2) When patient is terminal (Japanese physicians)

i. "After the initial shock of the diagnosis has worn off."

ii. "When the need for terminal care or pre-terminal care arises."

iii. "When it's difficult to continue the aggressive treatment / when the disease is too aggressive."
1) When patient has multiple chronic conditions (American physicians)

i. "After a few visits for chronic medical conditions for patients with an extensive list of medical conditions"

ii. "Diagnosis."

2) When patient is near death or terminal (American physicians)

i. "When intervention will not improve quality of life."

ii. "When death is assured."

iii. "Near end."

\section{Discussion}

There remains an incongruity between recognizing the importance of ACP and actively engaging in it, as shown by the disproportionate number of physicians in both countries that do not have an $\mathrm{AD}$ on file. It therefore came as no surprise that many physician respondents felt that additional training on ACP would be at least moderately helpful, especially on how to understand and discuss the topics of death and dying. It was surprising to see that Japanese physicians were less satisfied of their understanding on cultural perspectives regarding ACP than their American counterparts, given that they were more homogeneous than the American physicians. 
A notable pattern emerged from the topics that both groups of physicians indicated they wanted to learn more about. Specifically, a recurring theme was on having difficult conversations, which included managing expectations, breaking the "bad" news," and even on how to optimize patient visits for such conversations. These results indicate that future trainings would provide benefit by developing the confidence of physicians to have these conversations. Additionally, the findings of a previous study suggested that having group conversations with other patients regarding advance care planning may increase the feasibility of this conversations. ${ }^{12}$ This methodology could be incorporated into the training curriculum.

Further study is recommended to investigate the impact of taking surveys such as this one on physicians. It would be interesting to assess if exposure to the survey questions caused long-term reflection, encouraged respondents to learn more about ACP, or to take action and prepare and file an $\mathrm{AD}$ if they had not done so already. It is important to note, that while the lack of appointment time was cited as the biggest barrier in both settings, as of January 1, 2016, USA Medicare now reimburses healthcare professionals, including physicians, for providing ACP as a separate service through CPT codes 99497 and $99498 .{ }^{13}$ There are no limits on how often these codes can be billed. ${ }^{13}$ This change in policy has the potential to directly address the top concern cited by both Japanese and American physicians in their qualitative responses regarding their greatest challenge to discussing ACP: inadequate time. This challenge was demonstrated by the quantitative findings of the survey that revealed $64 \%$ of Japanese physicians and $76 \%$ of American physicians reported they felt they had too little, or far too little time to discuss ACP with patients. These findings also underscore the importance of ensuring that physicians are adequately trained and confident to take advantage of this endorsement of ACP by Medicare. Hence a future study is recommended to assess the impact of this important policy change.

In conclusion, findings revealed that although physicians from both medical centers recognized the importance of ACP, they appeared to not engage in its practice themselves, as evident by how most Japanese physicians (91\%) and more than half of US physicians (53\%) did not have an AD on file. Findings also indicated that in both medical centers, most physicians were not aware of community, social support, and educational resources for patients and their families on $\mathrm{ACP}$, as well as the resources available for ACP and decision making for them. Overall, the physicians appeared to believe that additional training on ACP would at least be a little helpful or greater benefit. In considering Medicare's reimbursement changes for ACP, additional training might be particularly helpful for USA based physicians. Hence further study is recommended to gauge the efficacy of trainings, as measured by physicians' self-reported confidence, knowledge, and practices regarding ACP.

\section{Acknowledgements}

We would like to express our gratitude to the participating physicians and administrators of the Japanese and Southern California Medical Centers for their support and participation in this study, without which this study would not have been possible.

\section{Declaration of conflicting interest}

The authors declared no potential conflicts of interest with respect to the research, authorship, and/or publication of this article.

\section{References}

1. Singer PA, Martin DK, Lavery JV, et al. Reconceptualizing advance care planning from the patient's perspective. Arch Intern Med. 1998;158(8):879-884.

2. Livingston G. Americans are aging, but not as fast as people in Germany, Italy and Japan. Fact Tank Pew Research Center; 2010.

3. Ortman JM, Velkoff VA, Hogan H. An aging nation: The older population in the United States. Washington, Census Bureau, USA: Springer; 2014. p. $25-1140$.

4. Scott IA, Mitchell GK, Reymond EJ, et al. Difficult but necessary conversations-the case for advance care planning. Med J Aust. 2013;199(10):662-666.

5. Schickedanz AD, Schillinger D, Landefeld CS, et al. A clinical framework for improving the advance care planning process: Start with patients' self-identified barriers. J Am Geriatr Soc.2009;57(1):31-39.

6. Thompson BT, Cox PN, Antonelli M, et al. Challenges in end-of-life care in the ICU: Statement of the 5th International Consensus Conference in critical care: Brussels, Belgium, April 2003: Executive summary. Crit Care Med. 2004;32(8):1781-1784.

7. Reinke LF, Slatore CG, Uman J, et al. Patient-clinician communication about end-of-life care topics: Is anyone talking to patients with chronic obstructive pulmonary disease. J Palliat Med. 2011;14(8):923-928.

8. Wenger NS, Carmel S. Physicians' religiosity and end-of-life care attitudes and behaviors. Mt Sinai J Med. 2004;71(5):335-343.

9. Kai I, Ohi G, Yano E, et al. Communication between patients and physicians about terminal care: A survey in Japan. Soc Sci Med. 1993;36(9):1151-1159.

10. Bito S, Asai A. Attitudes and behaviors of Japanese physicians concerning withholding and withdrawal of life-sustaining treatment for end-of-life patients: Results from an internet survey. BMC Med Ethics. 2007;8(1):7.

11. Nakazawa K, Kizawa Y, Maeno T, et al. Palliative care physicians' practices and attitudes regarding advance care planning in palliative care units in Japan A nationwide survey. Am J Hosp Palliat Med. 2013;31(7):699-709.

12. Lum HD, Jones J, Matlock DD, et al. Advance care planning meets group medical visits: The feasibility of promoting conversations. Ann Fam Med. 2016;14(2):125-132.

13. Frequently asked questions about billing the physician fee schedule for advance care planning services. Centers for Medicare and Medicaid Services. 2016. p. 1-3. 